\title{
Analysis of Damage Process in High Arch Dam Subjected to Strong Earthquake \\ Heng $\mathrm{CHENG}^{1, \mathrm{a}}$, Guo-Xin ZHANG ${ }^{1, b}$
}

${ }^{1}$ State Key Laboratory of Simulation and Regulation of Water Cycle in River Basin, China Institute of Water Resources and Hydropower Research, Beijing, 100038, China

achengheng1020@sina.com, 'bx-zhang@iwhr.com

Keywords: Concrete Damage, Strong Earthquake, High Arch Dam, Radiation Damping, Contact Nonlinearity.

\begin{abstract}
In the paper, the nonlinear seismic response of Shapai arch dam subjected to strong earthquake is analyzed by FEM time history analysis method. In the analysis, several comprehensive influencing factors, including infinite foundation radiation damping, damage of concrete, the contact nonlinearity of the transverse joints and sliding surface, and the nonlinearity of fractured rock on dam foundation, are taken into account to study their effects on seismic safety of arch dam. Through a study of damage extent in the arch dam, aseismic safety of the dam is evaluated.
\end{abstract}

\section{Introduction}

Most high arc dams are built in the western region in China, while the west region is the major strong earthquake area. The serious secondary disasters will be caused in downstream areas, once the dams are destroyed subjected to strong earthquake. Therefore, research on damage process of arch dam under strong earthquake is important to evaluate seismic safety of high arch dam.

The seismic response of high arch dam subjected to strong earthquake is affected by a combination of many factors, including nonlinear behavior of concrete[1], infinite foundation radiation damping[2], contact nonlinearity of the transverse joints and sliding surface[3], nonlinearity of fractured rock on dam foundation, and so on. Although researchers have made advances in studying the seismic safety of high arch dams by taking into account some influencing factors already mentioned in the literature, a more realistic evaluation of the seismic safety of high arch dams must be based on comprehensive simulation results that account for all of the key influencing factors. In this paper, a three dimensional numerical simulation model, which takes into account the comprehensive influencing factors for the damage process caused by strong earthquake, is established based on S hapai high arch dam. The damage extent of the arch dam under strong earthquake is analyzed, and the aseismic safety of the dam is studied.

\section{Damage Constitutive Model for Concrete}

The stress-strain relations for concrete can be expressed as

$$
\boldsymbol{\sigma}=(1-D) \tilde{\boldsymbol{\sigma}}=(1-D) \mathbf{E}_{0}:\left(\boldsymbol{\varepsilon}-\boldsymbol{\varepsilon}^{\mathrm{p}}\right)
$$

where $\boldsymbol{\sigma}=$ true stress tensor; $\tilde{\boldsymbol{\sigma}}=$ effective tress tensor; $\mathbf{E}_{\mathbf{0}}=$ elastic stiffness tensor when the concrete is not damaged; $\boldsymbol{\varepsilon}=$ total strain tensor; $\boldsymbol{\varepsilon}^{\mathrm{p}}=$ plastic strain tensor; $D=$ damage variable.

The plastic strain rate can be determined by plastic flow rule as

$$
\dot{\boldsymbol{\varepsilon}}^{p}=\dot{\lambda} \frac{\partial \Phi(\tilde{\boldsymbol{\sigma}})}{\partial \tilde{\boldsymbol{\sigma}}}
$$

where $\Phi=$ plastic potential function, which can be defined as 


$$
\Phi=\alpha_{p} \tilde{I}_{1}+\sqrt{2 \tilde{J}_{2}}
$$

where $\lambda=$ plastic invariant; $\tilde{I}_{1}=$ first invariant of effective stress tensor; $\tilde{J}_{2}=$ second invariant of deviatoric effective stress tensor; $\alpha_{p}=$ coefficient of plastic potential function.

The yield function proposed by Lubliner[4,5] is utilized as the yield criterion of concrete, which is written as

$$
\begin{aligned}
& F\left(\tilde{\sigma}, \varepsilon^{p}\right)=\frac{1}{1-\alpha}\left(\alpha \tilde{I}_{1}+\sqrt{3 \tilde{J}_{2}}+\beta\left(\varepsilon^{p}\right)\left\langle\hat{\tilde{\sigma}}_{\max }\right\rangle\right)-\tilde{\sigma}_{c}\left(\varepsilon_{c}^{p}\right) \\
& \alpha=\frac{\sigma_{b 0}-\sigma_{c 0}}{2 \sigma_{b 0}-\sigma_{c 0}} \\
& \beta\left(\varepsilon^{p}\right)=\frac{\tilde{\sigma}_{c}\left(\varepsilon_{c}^{p}\right)}{\tilde{\sigma}_{t}\left(\varepsilon_{t}^{p}\right)}(1-\alpha)-(1+\alpha)
\end{aligned}
$$

where $\hat{\tilde{\sigma}}_{\max }=$ algebraically maximum principal stress, $\langle x\rangle=(|x|+x) / 2 ; \sigma_{b 0}, \sigma_{c 0}=$ initial yield stresses for biaxial compression, uniaxial compression; $\tilde{\sigma}_{c}\left(\varepsilon_{c}^{p}\right), \tilde{\sigma}_{t}\left(\varepsilon_{t}^{p}\right)=$ uniaxial compressive and tensile strength function, respectively.

The tensile strength of concrete is much lower than the compressive strength. Therefore, the damage of concrete is mainly caused by tensile stress which exceeds the tensile strength of concrete. In this paper, the damage evolution for concrete under tension is studied. For uniaxial stress state, the stress-strain relation for concrete is expressed as

$$
\sigma\left(\varepsilon_{t}\right)=\left\{\begin{array}{ccc}
E_{0} \varepsilon_{t} & , \quad \varepsilon_{t} \leq \varepsilon_{0} \\
f_{t 0} e^{-a\left(\varepsilon_{t}-\varepsilon_{0}\right)} & , \quad \varepsilon_{t}>\varepsilon_{0}
\end{array}\right.
$$

where $f_{t 0}=$ tensile strength when concrete is not damaged; $\varepsilon_{0}=$ cracking strain of concrete; $a=$ softening coefficient which is related with fracture energy of concrete.

In general, the FEM calculation results are influenced by the finite element size. In order to avoid this phenomenon, the softening coefficient $a$ is defined as

$$
a=\frac{f_{t 0} l_{t}}{G_{f}}
$$

where $G_{f}=$ fracture energy $; l_{t}=$ characteristic length of finite element.

The stiffness of tensile damaged concrete under pressure can be recovered subjected to earthquake. Therefore, a weight factor $r(\hat{\tilde{\sigma}})$ is introduced to model the above phenomenon in this paper. The weight factor $r(\hat{\tilde{\sigma}})$ is defined as

$$
r(\hat{\tilde{\sigma}})=\sum_{i=1}^{3}\left\langle\hat{\tilde{\sigma}}_{i}\right\rangle / \sum_{i=1}^{3}\left|\hat{\tilde{\sigma}}_{i}\right|
$$

The degradation damage variable under multiaxial stress state is defined as

$$
D=r(\hat{\tilde{\sigma}})\left(1-\frac{\varepsilon_{0}}{\varepsilon_{1}-\varepsilon_{t \max }^{p}} \cdot e^{-a\left(\varepsilon_{1}-\varepsilon_{0}\right)}\right)
$$


where $\varepsilon_{1}=$ the first principal strain, $\varepsilon_{t \max }^{p}=$ the algebraically maximum eigenvalues.

\section{Analysis of Damage Process in High Arch Dam}

\section{Generation of Finite-element Mesh}

In the paper, the nonlinear seismic response of Shapai arch dam subjected to strong earthquake is analyzed by FEM time history analysis method. The maximum dam height of the arch dam is $130 \mathrm{~m}$. The normal storage water level is $1866 \mathrm{~m}$, and the silt elevation is $1796 \mathrm{~m}$, and the dry density of the silt is $500 \mathrm{~kg} / \mathrm{m}^{3}$. The fig. 1 and fig. 2 show the whole finite element model and the front view from upstream, respectively.

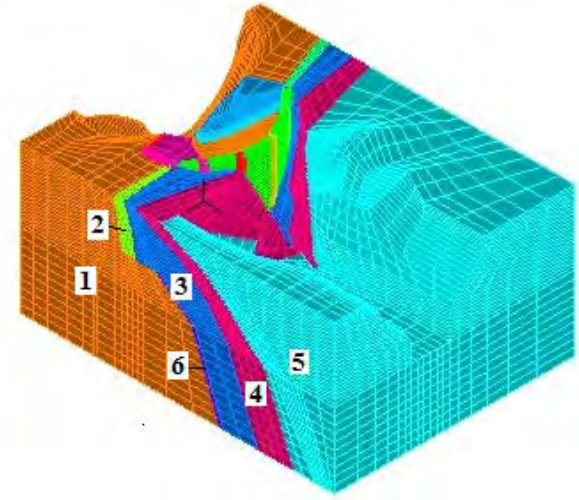

Fig. 1 Whole Finite Element Model

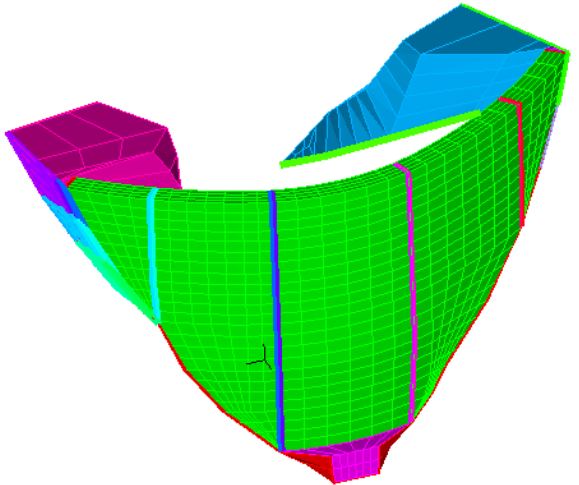

Fig. 2 The Front View from Upstream of the Dam

For the dam concrete, the modulus of elasticity $E_{0}=18 \mathrm{GPa}$, the poisson ratio $\mu=0.167$, the density $\rho=2400 \mathrm{~kg} / \mathrm{m}^{3}$, the damping ratio $\xi=0.05$, the linear thermal expansion coefficient $\alpha=1.0 \times 10^{-5} /$ ${ }^{\circ} \mathrm{C}$, the maximum tensile strength $f_{t}^{\prime}=3.25 \mathrm{MPa}$, the maximum compressive strength $f_{c}^{\prime}=25 \mathrm{MPa}$. For the foundation rock, the material parameters are shown in table1.

Tab. 1 Material Parameters of Foundation Rock

\begin{tabular}{|c|c|c|c|c|c|}
\hline Rock types & $\begin{array}{c}\text { Modulus of elasticity } \\
\mathrm{E}(\mathrm{GPa})\end{array}$ & $\begin{array}{c}\text { Poisson ratio } \\
\mu\end{array}$ & $\begin{array}{c}\text { Friction angle } \\
\varphi\left(^{\circ}\right)\end{array}$ & $\begin{array}{c}\text { Cohesion } \\
\mathrm{c}(\mathrm{MPa})\end{array}$ & $\begin{array}{c}\text { Density } \\
\rho\left(\mathrm{kg} / \mathrm{m}^{3}\right)\end{array}$ \\
\hline 1 & 17.5 & 0.23 & 50.19 & 1.2 & 2700 \\
\hline 2 & 11.0 & 0.25 & 45.00 & 1.0 & 2700 \\
\hline 3 & 9.0 & 0.26 & 35.75 & 0.20 & 2700 \\
\hline 4 & 5.0 & 0.30 & 33.82 & 0.20 & 2600 \\
\hline 5 & 9.0 & 0.27 & 33.02 & 0.20 & 2600 \\
\hline 6 & 5.0 & 0.31 & 30.96 & 0.30 & 2700 \\
\hline
\end{tabular}

Tab. 2 Strength Parameters of Potential Sliding Surface

\begin{tabular}{|c|c|c|}
\hline \multirow{2}{*}{} & \multicolumn{2}{|c|}{ Shear strength } \\
\cline { 2 - 3 } & Friction coefficient $f$ & Cohesion c(MPa) \\
\hline Lateral sliding surface in left bank & 0.99 & 0.86 \\
\hline Bottom sliding surface in left bank & 1.11 & 1.10 \\
\hline Lateral sliding surface in right bank & 1.00 & 0.88 \\
\hline Bottom sliding surface in right bank & 1.12 & 1.13 \\
\hline
\end{tabular}

In the paper, the induced joints of the Shapai arch dam are treated as the transverse joints. The contact nonlinearity of the transverse joints and the potential sliding surface in foundation rock are simulated by the constraint function method[6,7]. For the transverse joints, the cohesion $\mathrm{c}=0 \mathrm{MPa}$, 
the friction coefficient $f=0.75$. For the potential sliding surface in foundation rock, the strength parameters are shown in table2.

\section{Seismic Loads}

In the paper, the damage process of Shapai arch dam is analyzed under the earthquake with exceeding probability $2 \%$ in 100 years $(\mathrm{P} 100=2 \%)$. The peak acceleration value of the earthquake is $4.52 \mathrm{~m} / \mathrm{s}^{2}$. The three different-phase acceleration time histories are input in three directions, and the vertical peak acceleration is $2 / 3$ times of the horizontal peak acceleration. The acceleration time histories are shown as Fig.3.

The 3D consistent equivalent viscous-spring artificial boundary element is developed by using the matrixes of general finite element to simulate the infinite foundation radiation damping, and the wave input method[8,9] is used to model the seismic loads. Calculating time step is $0.02 \mathrm{~s}$, and the total calculating time is $43 \mathrm{~s}$.

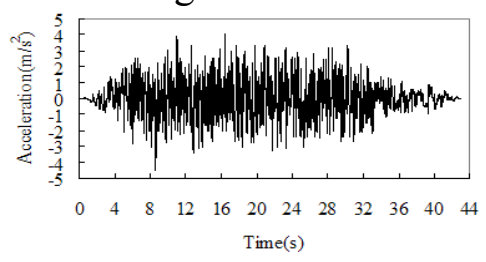

(a) transversal direction

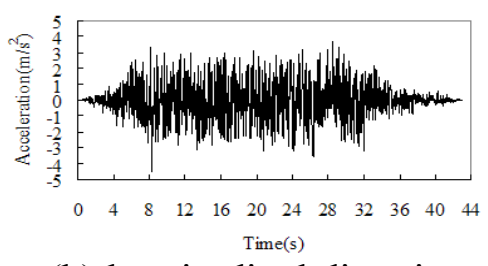

(b) longitudinal direction

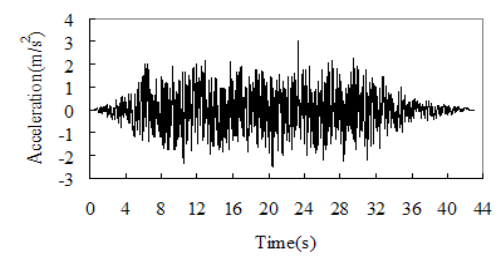

(c) vertical direction

Fig. 3 Acceleration Time Histories

\section{Damage Process of the Dam}

Fig.4 Fig.7 gives damage distribution of the dam at different earthquake time. In the initial earthquake stage, the upstream face of arch end, the dam heel, and the pedestal are damaged caused by the high tensile stress of these regions, of which the values surpass the concrete tensile strength. At $8.44 \mathrm{~s}$, the damage regions propagate to the upper part of the dam. With earthquake continuing, the damage to the dam becomes more serious. At $9.54 \mathrm{~s}$, besides the damage on upstream face of arch end, the additional damage zone is localized on the downstream face nearby the middle and upper part of arch crown. When the earthquake ends, the ranges of the damage on the downstream face and the upstream face of the right arch end enlarge. but the cracks at the base remain stable and do not propagate further.

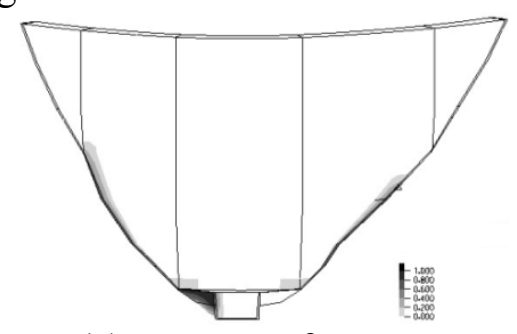

(a) upstream face

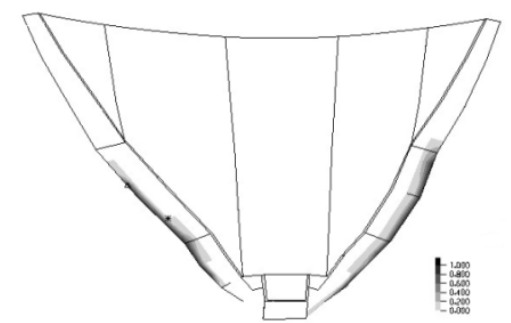

(b) downstream face

Fig. 4 Damage Distribution of the Dam at 3.72s

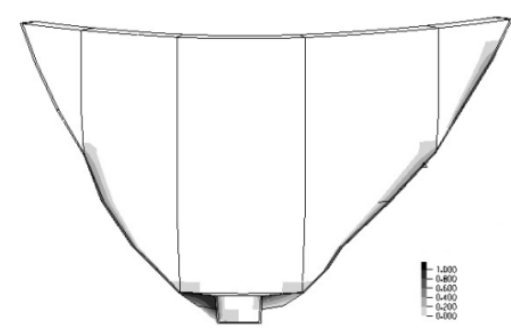

(a) upstream face

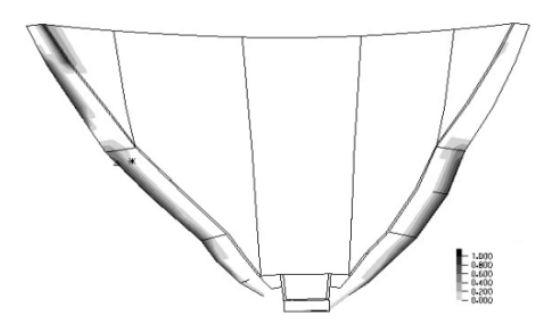

(b) downstream face

Fig. 5 Damage Distribution of the Dam at $8.44 \mathrm{~s}$ 


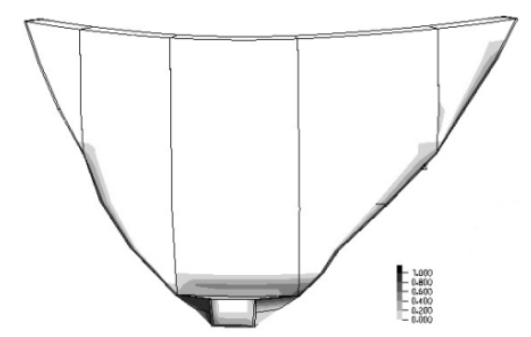

(a) upstream face

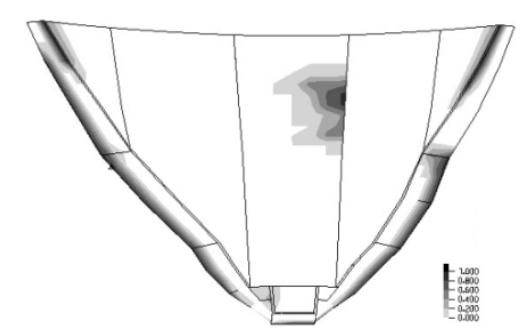

(b) downstream face

Fig. 6 Damage Distribution of the Dam at 9.54s

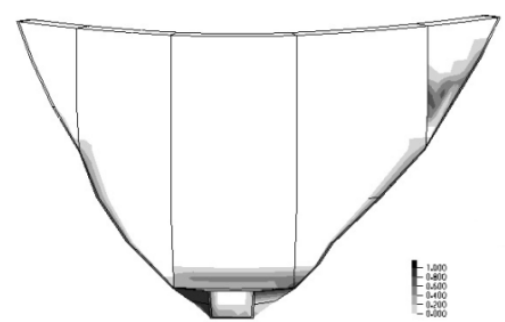

(a) upstream face

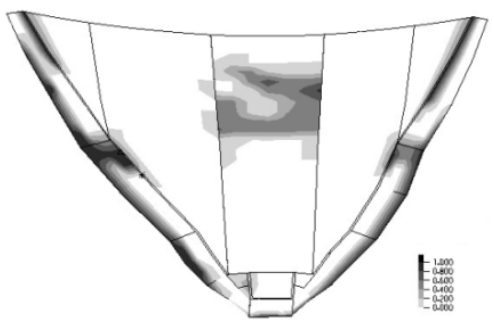

(b) downstream face

Fig. 7 Damage Distribution when the Earthquake Ends

Through the above analysis we realize that the concretes on the upstream face of the arch end, the dam heel as well as the middle and upper part of the downstream face may present damage, but have not formed penetrated damage zone, which indicates that the dam only surfers local damage but no catastrophic degradation.

\section{Conclusions}

In the paper, several comprehensive influencing factors, including infinite foundation radiation damping, damage of concrete, the contact nonlinearity of the transverse joints and sliding surface, and the nonlinearity of fractured rock on dam foundation, are taken into account to study the damage process of Shapai arch dam subjected to strong earthquake. Under earthquake with exceeding probability $2 \%$ in 100 years (peak acceleration $=4.52 \mathrm{~m} / \mathrm{s}^{2}$ ), the concretes on the upstream face of the arch end, the dam heel as well as the middle and upper part of the downstream face may present damage, but have not formed penetrated damage zone, which indicates that the dam only surfers local damage but no catastrophic degradation.

\section{Acknowledgement}

This research was financially supported by the Postdoctoral Science Foundation(2013M540989), National "973" program research project(2013CB035904, 2013CB036406), National 12th five-year technical support plan(SQ2013BAJY4138B02).

\section{References}

[1]National Research Council, Earthquake Engineering for Concrete Dams: Design, Performance, and Research Needs, National Academy Press, 1990..

[2]Gu Yin, Liu Jingbo, Du Yixin. 3D consistent viscous-spring artificial boundary and viscous-spring boundary element[J]. Engineering Mechanics, 2007, 24(12): 31 37.

[3]Lin Gao, Hu Zhiqiang, Chen jianyun. Dynamic analysis of an arch dam considering the effects of contraction joints[J]. Earthquake Engineering and Engineering Vibration, 2004, 24(6): 45-52.

[4]J. Lubliner, J. Oliver, S. Oller, E. Onate. A plastic-damage model for concrete[J]. International Journal of Solids and Structures, 1989, 25(3): 299-326. 
[5]Lee J, Fenves L G. Plastic-damage model for cyclic loading of concrete structures[J]. Journal of Engineering Mechanics, 1998, 124(8): 892-900.

[6]Bathe K J, Chaudhary A. A solution method for planar and axisymmetric contact problems[J]. Int. J. Num. Meth. in Eng., 1985, 21:65-88.

[7]Eterovic A, Bathe K J. On the treatment of inequality constraints arising from contact conditions in finite element analysis[J]. Computers and Structures, 1991, 40(2): 203-209.

[8]Du Xiuli, Zhao Mi. Analysis method for seismic response of arch dams in time domain based on viscous-spring artificial boundary condition[J]. Journal of Hydraulic Engineering, 2006, 37(9): 1063-1069.

[9]Cheng Heng, Zhang Liaojun, Zhang Hanyun. Application of 3D consistent equivalent viscous-spring boundary element to seismic analysis of arch dams[J]. Journal of Hydroelectric Engineering, 2009, 28(5): 169-173. 